\title{
Parts Feeding in Two-Stage Assembly Systems: An Assessment by Simulation
}

\author{
Matthias Thürer* (corresponding author) Nuno O. Fernandes and Mark Stevenson
}

\author{
Name: $\quad$ Prof. Matthias Thürer \\ Institution: Jinan University \\ Address: $\quad$ School of Intelligent Systems Science and Engineering \\ Jinan University (Zhuhai Campus) \\ 519070, Zhuhai, PR China \\ E-mail: $\quad$ matthiasthurer@workloadcontrol.com \\ Name: $\quad$ Professor Nuno O. Fernandes \\ Institution 1: Instituto Politécnico de Castelo Branco \\ Address: $\quad$ Av. do Empresário \\ 6000-767 Castelo Branco - Portugal \\ Institution 2: University of Minho \\ Address: $\quad$ ALGORITMI Research Unit \\ 4710-057 Braga - Portugal \\ Email: $\quad \underline{\text { nogf@ipcb.pt }}$ \\ Name: $\quad$ Prof. Mark Stevenson \\ Institution: Lancaster University \\ Address: Department of Management Science \\ Lancaster University Management School \\ Lancaster University \\ LA1 4YX - U.K. \\ E-mail: $\quad$ m.stevenson@lancaster.ac.uk
}

Keywords: Operations Management; Design Methodology - Design for assembly; Just-in-time (JIT) systems. 


\title{
Parts Feeding in Two-Stage Assembly Systems: An Assessment by Simulation
}

\begin{abstract}
Literature on two-stage assembly systems typically assume that parts (subassemblies) require several sequential operations at the first production stage. However, parts can often be produced at a single station. This shifts the focus away from coordination to the provision of parts. The literature on parts feeding typically assumes the full availability of parts at stock points (e.g. warehouses or supermarkets), thereby neglecting the potential impact of capacity constraints at upstream stations. In response, this study assesses the performance of different parts feeding policies (kitting and line stocking). Simulation results show limited operational performance differences between kitting and line stocking in to-stock systems, with the main difference being where stock points are located. However, results also highlight the potential for producing subassemblies to-order if the constraint is how much (and not where) stock can be kept. This links together the literature on parts feeding with that on customer order decoupling points.
\end{abstract}

Keywords: Operations Management; Design Methodology - Design for assembly; Just-in-time (JIT) systems. 


\section{Introduction}

This study is motivated by an assemble-to-order company that produces parts or subassemblies in a subassembly shop that are then assembled into the end product, or final assembly, at an assembly shop. This type of shop is commonly encountered in practice (e.g. Silva et al. 2006; Stevenson \& Silva, 2008; Hendry et al., 2008; Stevenson et al., 2011) and there exists a broad literature on both assembly shops and multi-stage shops (e.g. Sculli, 1980; Adam et al., 1987; Philipoom et al., 1991; Portioli-Staudacher, 2000; Lu et al., 2011; Thürer et al., 2012, 2012b). This literature typically assumes that subassemblies require several independent processing operations (Komaki et al. 2019). In this context, a major challenge is the coordination of the subassemblies on the shop floor such that all subassemblies that make up an assembly order arrive at the assembly shop in time (Thürer et al., 2012; Chen et al., 2019). But in some practical situations, subassemblies may have simple routings, such as in the case of plastic molds, and only require processing at a single station or cell. In this context, the focus shifts from co-ordinating subassembly progress to parts feeding.

Two commonly known parts feeding policies are line stocking and kitting (Bozer \&McGinnis, 1994, Hua \& Johnson, 2010). Line stocking provides the continuous replenishment of parts or subassemblies to the assembly line, typically using a reorder point system. In contrast, kitting requires that all subassemblies of an assembly order are combined in a so-called kit before being sent to assembly. Thus, with kitting, usually no stocks of parts are kept at the assembly stations. While there has been increasing research interest on parts feeding (see, e.g. Kilic \& Durmusoglu, 2015; Schmid \& Limère, 2019), existing studies mostly focus on analytical models, neglecting stochastic demand systems. Moreover, to the best of our knowledge, existing studies only focus on the assembly operations downstream of subassembly stock points, such as a warehouse (including some studies on the design of the warehouse (e.g. Battini et al. 2015)). This neglects the subassembly shop, which is upstream of these stock points, and consequently the potential impact of capacity shortages at subassembly stations that may result in stock-outs. This is a major shortcoming given contradicting results on the recommended feeding policy, when taking the literature on both assembly parts-feeding and multi-stage shops into account. While Hua \& Johnson (2010) argued that in a to-order environment, where component variety is high, kitting would be a better option than line stocking, Thürer et al. (2013) found that in a high variety multistage shop, the assembly order should be released to the assembly shop as soon as the first subassembly in its routing becomes available, rather than only when all of the subassemblies that 
make up an assembly order are completed and become available at the assembly shop (as would be the case for kitting).

In response, this study uses simulation to assess the performance of different parts feeding policies in a two-stage assembly system. The first stage produces parts or subassemblies that are produced at several single stations. The second stage assembles these subassemblies into the end product requiring multiple sequential operations at different assembly stations. This extends the existing literature on multi-stage systems that focused on the co-ordination of subassemblies with independent routings and the literature on parts-feeding that neglected the subassembly shop altogether.

The remainder of this paper is structured as follows. Both strands of literature of relevance to our study - two-stage assembly systems and parts feeding - are reviewed in Section 2, where our research question is also outlined. The simulation model used to evaluate the performance of the different feeding policies is then described in Section 3 before the results are presented, discussed, and analyzed in Section 4. Finally, conclusions are provided in Section 5.

\section{Literature Review}

While there exists a large literature on two-stage assembly flow shops (Allahverdi \& Aydilek, 2015; Komaki \& Kayvanfar, 2015; Nejati et al., 2016; Seidgar et al., 2016; Sheikh et al. 2018), studies in this literature typically assume a single feeding and assembly station in a deterministic context. In contrast, this study assumes a series of assembly operations that are fed by a subassembly shop consisting of several single stations where demand, processing times, and due dates are stochastic. The literature on two-stage assembly flow shops is therefore neglected. The same holds for research that has focused on scheduling (e.g. Pongcharoen et al., 2002; Thiagarajan \& Rajendran, 2005), since studies in this literature usually assume demand to be deterministic. In contrast, we assume a stochastic to-order context.

\subsection{Assembly Parts-Feeding and Multi-Stage Shops}

A broad literature exists on dispatching in assembly shops (e.g. Sculli, 1980; Adam et al., 1987; Philipoom et al., 1991). Most of the rules described in this body of work base the dispatching decision on the remaining work orders, such as the Number of Unfinished Parts (NUP) rule (e.g. Maxwell \& Mehra, 1968) or the unfinished work content of an assembly order. Lu et al. (2011) compared these rules with simple First-Come-First-Served (FCFS) and Earliest Due Date (EDD) 
dispatching. Meanwhile, Bertrand \& van de Wakker (2002) used Operation Completion Dates (OCDs) which led to the best performance in Thürer et al. (2012).

Bertrand \& van de Wakker (2002), Lu et al. (2011), and Thürer et al. (2012) have also contributed to the available literature on order release in assembly shops - i.e. where subassemblies produced in a job shop are assembled at one final assembly station. Meanwhile, Thürer et al. (2013) considered order release in a multi-stage system while Fernandes et al. (2015) considered a two-stage production system with an intermediate buffer of semi-finished products. Stage one has only a single station that is the first in the routing of all manufactured products and stage two is a multi-station shop. Above studies confirmed the positive impact of order release, while Thürer et al. (2013) further found that an assembly order should be released to the assembly shop as soon as the first subassembly in its routing is finished, rather than only when all of the subassemblies that make up an assembly order are complete.

A main observation that can be made from the existing literature is that most of the studies assume that subassemblies require several operations. Consequently, the co-ordination of subassembly progress is the main challenge. The only exception is Fernandes et al. (2015), but these authors only considered a common preceding station to all products.

\subsection{Kitting vs. Line Stocking}

While there exists an increasing literature on feeding policies, see e.g. Kilic \& Durmusoglu (2015) and Schmid \& Limère (2019) for some recent reviews, studies in this literature typically neglect stochastic demand. Rather, it uses analytical models for cost, feeding time, work-in-process and space requirements. For example, Sali et al. (2015) compared three different line feeding policies - Line Stocking, Kitting and Sequencing - in terms of cost. They found that line stocking yields its best performance for big components having low diversity; that kitting is more convenient for small components with high diversity; and that sequencing is more convenient for big components with high diversity. Meanwhile, Limère et al. (2012) showed that hybrid policies, where some parts will be kitted while others will be stocked in bulk at the line, are preferred to the exclusive use of either parts feeding system. This finding is also supported by Hanson \& Brolin (2013) who analyzed two case companies that moved from line stocking to kitting. Finally, analytical models

for feeding time have been presented by Battini et al. (2009) while Bozer \& McGinnis (1992) also provided a model to estimate the impact of different feeding policies on work-in-process and space requirements. 
There are two general observations to be made on the above. First, that stochastic to-order contexts are widely neglected in the literature. Second, that existing studies focus on the assembly operations downstream of subassembly stock points (such as a warehouse or a supermarket) thereby neglecting the impact of upstream operations producing the subassemblies.

\subsection{Discussion of the Literature}

The literature on assembly shops typically focuses on subassembly co-ordination in the context of material flow control (Graves et al. 1995). Order release and dispatching rules introduced in this literature seek to co-ordinate the progress of the different subassembly orders that make up the assembly order. However, in practice, subassemblies may often be produced at a single station or cell; for example, plastic injection components. In this scenario, the focus shifts away from the coordination of subassembly progress on the shop floor towards the replenishment of parts.

However, while there exists a broad literature that seeks to assess the advantages of different parts feeding policies, such as line stocking and kitting, studies typically consider deterministic contexts and only focus on the operations after subassembly stock points. The former is a major shortcoming since it neglects systems in which demand follows a stochastic process. It also neglects the possibility of parts stock-outs; in general, it is assumed that stocking points always have subassemblies (parts) available. This directly relates to the latter, since stock-outs may be induced by capacity shortages at stations upstream of the subassembly stock points.

Therefore, there is a need for further research on feeding policies that considers both, the subassembly and the assembly shops. This is also highlighted by contradictory findings on which feeding policy to apply. Hua \& Johnson (2010) argued that in a to-order environment where component variety is high, kitting would be a better option than line stocking. But this means that the release of the different parts that make up the assembly order is synchronized. All parts enter the assembly system as one kit. In contrast, line stocking allows for releasing the assembly order immediately. Thürer et al. (2013) found that in a high variety multi-stage assembly shop, the assembly order should be released to the assembly shop as soon as the first subassembly in its routing becomes available, rather than only when all of the subassemblies that make up an assembly order are completed and become available. In response, this study asks: 
What feeding policy (kitting or line stocking) should be applied in two-stage assembly systems, where the first stage provides subassemblies that can be produced at a single station or cell for a second stage consisting of multiple assembly stations?

Discrete event simulation will be used to answer this question.

\section{Simulation Model}

\subsection{Overview of Modeled Shop and Order Characteristics}

A simulation model of a two-stage assembly system has been developed using SIMIO $\odot$. We have kept our system relatively small, since this allows causal factors to be identified more easily. Small systems provide a better insight into the role of operating variables and, in practice, large systems can often be decomposed into several smaller systems (Bokhorst et al. 2004). So, each stage consists of three stations and each station is a single and constant capacity resource. All of the subassemblies of an assembly order are produced at Stage 1, the subassembly shop, and then proceed to Stage 2, the assembly shop, following a feeding policy as described in Section 3.2 below. At the assembly shop, parts or subassemblies are assembled into the end products through a series of sequential assembly operations. The two stages can be further described as follows:

- Subassembly Shop (Stage 1): Each station produces a given number of subassemblies variants. The number of variants that can be produced at each station is an experimental factor and it is varied from 2 to 4, similar to previous research (e.g. Sali et al., 2015).

- Assembly Shop (Stage 2): Each assembly station receives subassemblies from a specific subassembly station. The number of operations per assembly (or end product) is uniformly distributed between one and three. All assembly stations have an equal probability of being visited and a particular station is required at most once in the routing of an assembly. Assembly order routings are sorted to create a dominant flow direction.

The due dates of assembly orders are set exogenously by adding a random allowance factor to the order entry time. The random allowance factor is uniformly distributed between 25 and 40 time units and has been set arbitrarily. The mean operation processing times at both the assembly and subassembly stations is equal to 1 time unit. The processing time is an experimental variable and can be constant or stochastic. In the latter case, the processing time follows a 2-Erlang distribution. 
Finally, the inter-arrival rate of assembly orders follows an exponential distribution with a mean of 0.741 time units, which deliberately results in a utilisation level of $90 \%$ at each station.

\subsection{Assembly Release and Parts Feeding Policy}

For all policies, assembly orders arriving at the system wait in a backlog. They are released to the assembly shop depending on subassembly availability. Classical line stocking and kitting produce subassemblies in advance of demand, i.e. to-stock. In this study we also consider the option of producing subassemblies only after demand occurred, i.e. to-order. This results in four different parts feeding policies as follows:

- Line stocking: Subassemblies are produced to-stock at subassembly stations using a reorder point logic. Stock is located at assembly stations. Three different levels for the reorder point were considered, namely: 2, 3 and 4 units per subassembly variant. The total amount of stock for each setting is kept equal to 24 units to ensure comparability across settings. Hence, a scenario with fewer variants has a higher reorder quantity, namely 12, 8 and 6 for a reorder point of 2, 3 and 4, respectively. The assembly order is released to the assembly shop if there is material stock for the subassembly needed at the first station in its routing, otherwise it must wait in the backlog until stock is available.

- 'Classical' kitting: Subassemblies are produced to-stock at subassembly stations using reorder point logic. Stock is located at the kitting station. Again, the same three different levels for the reorder point and reorder quantity are considered and the total amount of stock is kept equal. The assembly order can only be released to the assembly shop if its kit is complete, i.e. if there is stock of all of the subassemblies needed. The kit moves with the assembly order through the assembly shop. There are no stock points at the assembly stations.

- Line feeding to-order: The exact amount of subassemblies is produced once the assembly order arrives. Once completed, subassemblies are sent to the stations where they are assembled. The assembly order is released to the assembly shop as soon as there is stock for the subassembly needed at the first station in its routing.

- Kitting to-order: The exact amount of subassemblies is produced once the assembly order arrives. A kit is routed through the subassembly shop and filled with the required subassemblies. Once the kit is complete, it is sent to the assembly shop and starts moving with the assembly order through the assembly shop. There are no stock points at the assembly stations. 
All four parts feeding policies are schematized in Figure 1. Meanwhile, transportation or moving times are assumed to be negligible for all policies so as to avoid distracting from the focus of our study. Finally, assembly production follows Earliest Due Date (EDD). Subassembly production follows first-come-first-served (FCFS) if production is to-stock and EDD if production is to-order. In the latter case, subassembly due dates are equal to the associated assembly due date. Note that we do not consider any further control policy, such as the use of an explicit order release function, to avoid distracting away from the core focus of our study - the parts feeding policy.

[Take in Figure 1]

\subsection{Experimental Design and Performance Measures}

The experimental factors considered are: the four parts feeding policies; the number of variants that can be produced at each subassembly station; and, the nature of the processing times (constant vs. stochastic). Note that we only consider two environmental factors. Additional experiments were conducted using different degrees of processing time variability, but these results did not affect conclusions and are thus not considered here. Experiments were full factorial. Since we have three settings for the reorder point and reorder quantity for the two to-stock parts feeding policies, a total of 48 experimental scenarios were executed ( $2 \times 3 \times 2 \times 3$ for to-stock plus $2 \times 3 \times 2$ for to-order). Each scenario was replicated 200 times while results were collected over 10,000 time units following a warm-up period of 3,000 time units. These parameters are in line with those used in previous studies (e.g. Thürer et al., 2013; Fernandes et al., 2015) and allow us to obtain stable results while keeping the simulation run time reasonable. Since we focus on a make-to-order assembly system, our main performance indicator will be delivery performance. Delivery performance will be measured by: the percentage of tardy assembly orders - the percentage of assembly orders completed after the due date; the mean tardiness of assembly orders, that is $T_{j}=\max \left(0, L_{j}\right)$, with $L_{j}$ being the lateness of the assembly order $j$ (i.e. the actual delivery date

minus the due date of assembly order $j$ ); and, the total throughput time of assembly orders, that is the mean of the completion date minus the entry date across assembly orders (this measure also indicates the lateness since due dates are set exogenously).

In addition, we also measure the shop throughput time of assembly orders, that is the time an assembly order actually spends on the assembly shop. Finally, the significance of performance 
differences between the outcomes of individual experiments were verified by paired t-tests, which comply with the use of common random number streams to reduce variation across experiments. Whenever we discuss a difference in outcomes between two experiments, the significance can be proven by a paired t-test at a level of $95 \%$.

\section{Results}

\subsection{Assessment of Results: Constant Processing Times}

The results of our simulation experiments, together with the $95 \%$ confidence intervals, are summarized in Table 1 for the scenarios with constant processing times. The following can be observed from our results:

- To-stock system: Line stocking and classical kitting perform statistically similar in terms of tardiness performance; i.e. the $95 \%$ confidence intervals overlap. The discrepancy between total throughput time and throughput time reflects stock-outs (i.e. the time the assembly order has to wait for its subassemblies). For line stocking, waiting occurs on the assembly shop floor. For classical kitting waiting occurs at the kitting station. Classical kitting therefore has a smaller assembly shop throughput time. As observed in previous literature, the major difference between policies is where parts physically wait.

- To-order system: Line feeding to-order significantly outperforms kitting to-order. Since production is to-order, subassembly stations only produce what is needed. Since processing times are constant and equal, stations are capable of producing subassemblies just-in-time with assembly shop throughput times being statistically equivalent for kitting to-order and line feeding to-order. However, kitting to-order has a longer total throughput time since assembly orders have to wait for synchronization. These results are in line with Thürer et al. (2013). Meanwhile, the number of part variants has no statistically significant impact on performance.

- Impact of control parameters (in the to-stock system): As somewhat expected, a higher reorder point leads to better tardiness performance in terms of both percentage tardy and mean tardiness. Meanwhile, a lower reorder quantity leads to better tardiness performance although the number of part variants increases. This is an effect of there being a finite subassembly capacity. Large reorder quantities block station capacity for a longer duration thereby creating excess inventory for one part variant while other part variants are actually missing. 
[Take in Table 1]

\subsection{Assessment of Results: Stochastic Processing Times}

Similar observations can be made for the results obtained for stochastic processing times. These results are given in Table 2 .

\section{[Take in Table 2]}

A main observation comparing the results in Table 1 and Table 2 is the increase in throughput times and total throughput times. As somewhat expected, throughput times increase due to variability in the processing times at the assembly stations. Meanwhile, total throughput times further increase because pool waiting times increase. For stochastic processing times, the pool waiting times increase because it is less likely that subassemblies are available due to increased congestion at subassembly stations. Consequently, the assembly order must wait longer in the pool until subassemblies become available.

\subsection{Discussion of Results}

There is only limited impact of upstream stations in a to-stock system in our simulated context if the parameters of the reorder point system are set appropriately. There is also little difference in terms of operational performance between line stocking and classical kitting. The main difference is where stock is created, this is the physical location of parts. This finding is in line with previous research on parts feeding (e.g. Hanson \& Brolin, 2013). It implies that the decision concerning which policy to apply largely depends on factors other than operational performance, such as where physical space is available, what transportation system is available, etc.

However, it should be noted that the amount of physical space, this is how much stock needs to be kept, does not change. The amount is the same for line stocking and classical kitting. If physical space is in general a constraint, then a to-order policy may be a better solution. There is no doubt that to-order policy realizes longer total throughput times. However, it does not require any stock and realizes comparable or even shorter assembly shop throughput times.

Pushing the customer order decoupling point (e.g. Sharman, 1984; van Donk, 2001; Calle et al., 2016) or order penetration point (e.g. Olhager, 2003) - this is the point in the product flow where parts wait to be assigned to customer (or in our case, assembly) orders - downstream reduces total throughput times. But it also creates more inventory in classical assembly systems. Our to- 
order policies shifted the order decoupling point upstream from after the subassembly shop to before the subassembly shop. This increased total throughput times but also avoided any stock after the subassembly shop. This finding extends literature on the positioning of customer order decoupling points which typically focusses on simple production lines (e.g. van Donk, 2001; Calle et al., 2016). It also aligns with findings in the parts feeding literature, for example, Bozer \& McGinnis (1992) who argued that assembling kits ahead of time and storing them until they are ready to be used - which means shifting the customer order decoupling point further downstream compared to classical kitting - will further increase the demand placed on the storage/retrieval system. Meanwhile, our simulation results highlight that, in a to-order context, line feeding outperforms kitting. This aligns with results in previous research on multi-stage to-order systems (e.g. Thürer et al., 2013).

\section{Conclusions}

Two-stage assembly systems are commonly encountered in practice. The first stage produces subassemblies that are then assembled at the second stage. As a consequence, a broad literature exists. One strand of this literature assumes that subassemblies require several sequential operations at the first production stage. Its main focus is consequently on coordinating subassembly progress, so all subassemblies of an assembly order arrive at the second stage on time. However, in practice, subassemblies can often be produced at a single station or cell. This shifts the focus away from coordination to parts feeding. While there exists a broad literature on parts feeding, studies typically assume the full availability of parts at stock points (e.g. warehouses or supermarkets), thereby neglecting the impact of upstream stations that replenish the stock points. In response, this study asked: What feeding policy (kitting or line stocking) should be applied in two-stage assembly systems, where the first stage provides subassemblies that can be produced at a single station or cell for a second stage consisting of multiple assembly stations? Using simulation, we showed that operational performance differences are limited. The main difference between classical kitting and line stocking is the location, i.e. where stock is located. As a result, other factors than operational performance determine the choice of parts feeding policy. However, we also highlighted the potential of producing parts to-order if the constraint is on how much stock can be kept. While producing to-order increases total throughput times, it 
eliminates stock. This links together the literature on parts feeding with that on customer order decoupling points.

\subsection{Managerial Implications}

Our study reemphasizes the important role of the customer order decoupling point. It extends existing literature on customer order decoupling points, which typically focuses on production lines, by highlighting its impact on stock size in assembly systems. There are two important questions for managers when deciding which parts feeding policy to choose: Is the storage space a constraint (How much)? Is the location of inventory a constraint (Where)? If the answer to the first question is yes, then line feeding to-order is likely to be the best choice since it eliminates stock and outperforms kitting to-order. If the answer to the first question is no, then the answer to the second question will determine which parts feeding policy to choose. If there is no space at the assembly shop, line stocking cannot be applied. Otherwise, both policies can be chosen and other criteria, such as the available transportation system, determine the decision.

\subsection{Limitations and Future Research}

A main limitation of our study is the simplicity of our modelled shop and the limited number of environmental factors. While we consider this to be justified by the focus of our study, future research could consider more complex assembly systems. This includes systems which have both subassemblies that require several operations and subassemblies that can be produced at a single station or cell. This introduces important trade-offs between parts feeding and coordination if the same resources are required by both types of subassemblies. More research is required to explore how best to handle these trade-offs. 


\section{About the Authors}

Matthias Thürer is Distinguished Professor in Management Science and Engineering at the Institute of Physical Internet, Jinan University (Zhuhai, PR China). Before getting involved in academia, Matthias worked in several companies, did an apprenticeship and became a master craftsman ('Meister'). Simple control for complex shops is one of Matthias' main research interests. He has published widely on production control systems and is a leading expert on Workload Control, COBACABANA (Control of Balance by Card Based Navigation) and Lean Work Design.

Nuno O. Fernandes is currently working as adjunct Professor at the Department of Electrical and Industrial Engineering at the Polytechnic Institute of Castelo Branco, Portugal. He received his Ph.D. degree in Production and Systems Engineering from the University of Minho, Portugal, in 2007. His research interests are in production planning and control (PPC) and simulation. He has published on these subjects in several international journals.

Mark Stevenson is a Professor of Operations Management at Lancaster University Management School (LUMS), Lancaster University, UK. He has published on a range of topics, including production planning and control in low-volume high-variety contexts. His work has appeared in leading operations and supply chain management journals, including the International Journal of Operations and Production Management, Production and Operations Management, Supply Chain Management: An International Journal, the International Journal of Production Economics, the International Journal of Production Research, and Production Planning and Control. Mark regularly attends the European Operations Management Association (EurOMA) conference and is a fellow of both the Chartered Management Institute (CMI) and the Higher Education Academy (HEA). 


\section{References}

Adam, N. R., Bertrand, J. W. M., and Surkis, J., 1987, Priority assignment procedures in multi level assembly job shops, IIE Transactions, 19, 3, 317 - 328.

Adam, N. R., Bertrand, J. W. M., Morehead, D. C., and Surkis, J., 1993, Due date assignment procedures with dynamically updated coefficients for multi level assembly jobs, European Journal of Operational Research, 68, 1, 212 - 227.

Allahverdi, A., and Aydilek, H., 2015, The two stage assembly flowshop scheduling problem to minimize total tardiness, Journal of Intelligent Manufacturing, 26, 225-237.

Battini, D., Gamberi, A., Persona, A., and Sgarbossa, F., 2015, Part-feeding with supermarket in assembly systems: transportation mode selection model and multi-scenario analysis, Assembly Automation, 35/1, 149-159.

Battini, D., Faccio, M., Persona, A., and Sgarbossa, F., 2009, Design of the optimal feeding policy in an assembly system, International Journal of Production Economics, 121, 233-254.

Bertrand, J.W.M., and Van de Wakker, A.M., 2002. An investigation of order release and flow time allowance policies for assembly shops, Production Planning and Control, 13, 7, 639 - 648.

Bokhorst, J.C.A., Slomp, J., \& Gaalman G.J.C., 2004, On the who-rule in Dual Resource Constrained (DRC) manufacturing systems, International Journal of Production Research, 42, 23, 5049-5074.

Bozer, Y.A, and McGinnis, L.F. 1992, Kitting versus line stocking: A conceptual framework and a descriptive model, International Journal of Production Economics, 28, 1-19.

Calle, M., González-R, P. L., Leon, J. M., Pierreval, H., and Canca, D., 2016, Integrated management of inventory and production systems based on floating decoupling point and realtime information: A simulation based analysis, International Journal of Production Economics, $181,48-57$.

Chen, J., Wang, M., Kong, X.T.R., Huang, G.Q., Dai, Q., and Shi G., 2019, Manufacturing synchronization in a hybrid flowshop with dynamic order arrivals, Journal of Intelligent Manufacturing, 30, 7, 2659-2668.

Fernandes, N.O., Silva, C., and Carmo-Silva, S., 2015, Order release in the hybrid MTO-FTO production, International Journal of Production Economics, 170, Part B, 513-520.

Graves, R.J., Konopka, J.M., and Milne, R.J., 1995, Literature review of material flow control mechanisms, Production Planning and Control, 6, 5, 395-403.

Hanson, R., and Brolin, A., 2013, A comparison of kitting and continuous supply in in-plant materials supply, International Journal of Production Research, 51, 4, 979-992.

Hendry, L.C., Land, M.J., Stevenson, M., and Gaalman, G., 2008, Investigating implementation issues for workload control (WLC): A comparative case study analysis, International Journal of Production Economics, 112, 452 - 469.

Hua, S.Y., and Johnson, D.J., 2010, Research issues on factors influencing the choice of kitting versus line stocking, International Journal of Production Research, 48, 3, 779-800.

Kilic, H.S., and Durmusoglu, M.B., 2015, Advances in assembly line parts feeding policies: a literature review, Assembly Automation, 35, 1, 57-68. 
Komaki, G.M., and Kayvanfar, V., 2015, Grey Wolf Optimizer algorithm for the two-stage assembly flow shop scheduling problem with release time, Journal of Computational Science, 8, 109-120.

Limère, V., Van Landeghem, H., Goetschalckx, M., Aghezzaf, E.H., and McGinnis, L.F., 2012, Optimising part feeding in the automotive assembly industry: deciding between kitting and line stocking, International Journal of Production Research, 50, 15, 4046-4060.

Lu, H. L, Huang, G. Q. and, Yang, H. D., 2011, Integrating order review/release and dispatching rules for assembly job shop scheduling using a simulation approach, International Journal of Production Research, 49, 3, 647 - 669.

Maxwell, W. L., and Mehra, M., 1968, Multiple-Factor rules for sequencing with assembly constraints, Naval Research Logistics Quarterly, 15, 241 - 254.

Nejati, M., Mahdavi, I, Hassanzadeh, R., and Mahdavi-Amiri, N., 2016, Lot streaming in a twostage assembly hybrid flow shop scheduling problem with a work shift constraint, Journal of Industrial and Production Engineering, 33, 7, 459-471.

Olhager, J., 2003, Strategic positioning of the order penetration point, International Journal of Production Economics, 85, 3, 319-329.

Philipoom, P., Russell, R., and Fry, T., 1991, A preliminary investigation of multi-attribute based sequencing rules for assembly shops, International Journal of Production Research, 29, 4, 739 $-753$.

Pongcharoen, P., Hicks, C., Braiden, P.M., and Stewardson D.J., 2002, Determining optimum Genetic Algorithm parameters for scheduling the manufacturing and assembly of complex products, International Journal of Production Economics, 78, 311 - 322.

Portioli-Staudacher, A., 2000, ISTS: a new procedure for the integrated scheduling of multi-stage systems, International Journal of Production Research, 38, 11, 2489 - 2514.

Sali, M., Sahin, E., and Patchong, A., 2015, An empirical assessment of the performances of three line feeding modes used in the automotive sector: line stocking vs. kitting vs. sequencing, International Journal of Production Research, 53, 5, 1439-1459.

Schmid, N.A., and Limère, V., 2019, A classification of tactical assembly line feeding problems, International Journal of Production Research, (in print)

Sculli, D., 1980, Priority dispatching rules in job shops with assembly operations and random delays, Omega, 8, 2, $227-234$.

Seidgar, H., Zandieh, M., and Mahdavi, I., 2016, Bi-objective optimization for integrating production and preventive maintenance scheduling in two-stage assembly flow shop problem, Journal of Industrial and Production Engineering, 33, 6, 404-425.

Sharman, G., 1984, The rediscovery of logistics, Harvard Business Review, (Sept-Oct), 71-79.

Sheikh, S., Komaki, G.M., Kayvanfar, V., 2018, Multi objective two-stage assembly flow shop with release time, Computers \& Industrial Engineering, 124, 276-292.

Silva, C., Roque, L., and Almeida, A., 2006, MAPP - A web-based decision support system for the mould industry, Decision Support Systems, 42, 2, 999 - 1014. 
Stevenson, M., and Silva, C., 2008, Theoretical development of a workload control methodology: Evidence from two case studies, International Journal of Production Research, 46, 11, 3107 3131.

Stevenson, M., Huang, Y., Hendry L.C., and Soepenberg, E., 2011, The theory \& practice of workload control: A research agenda \& implementation strategy, International Journal of Production Economics, 131, 2, 689 - 700.

Thiagarajan, S., and Rajendran, C., 2005, Scheduling in dynamic assembly job-shops to minimize the sum of weighted earliness, weighted tardiness and weighted flow time of jobs, Computers \& Industrial Engineering, 49, 463 - 503.

Thürer, M., Stevenson, M., Silva, C., Land, M.J., and Godinho Filho, M., 2013, Workload Control and Order Release in Two Level Multi-Stage Job Shops: An Assessment by Simulation; International Journal of Production Research, 51, 3, 869-882.

Thürer, M., Stevenson, M., Silva, C., and Huang, G.Q., 2012, The Application of Workload Control in Assembly Job Shops: An Assessment by Simulation, International Journal of Production Research, 50, 18, 5048-5062.

van Donk, D. P., 2001, Make to stock or make to order: The decoupling point in the food processing industries, International Journal of Production Economics, 69, 3, 297-306. 
Table 1: Results for different Parts Feeding Policies and Constant Processing Times

\begin{tabular}{|c|c|c|c|c|c|c|c|}
\hline & \multirow{2}{*}{$\begin{array}{l}\text { Part } \\
\text { Variants }\end{array}$} & \multirow{2}{*}{$\begin{array}{l}\text { Reorder } \\
\text { Point }\end{array}$} & \multirow{2}{*}{$\begin{array}{l}\text { Reorder } \\
\text { Quantity }\end{array}$} & \multicolumn{4}{|c|}{ Assembly Order } \\
\hline & & & & TTT & TT & \%tardy & Tard. \\
\hline \multirow{9}{*}{$\begin{array}{l}\text { Line } \\
\text { Stocking }\end{array}$} & 2 & 2 & 12 & $10.08 \pm 0.14$ & $8.69 \pm 0.09$ & $3.78 \pm 0.28$ & $0.27 \pm 0.03$ \\
\hline & 3 & 2 & 8 & $9.34 \pm 0.12$ & $8.51 \pm 0.09$ & $2.79 \pm 0.22$ & $0.18 \pm 0.03$ \\
\hline & 4 & 2 & 6 & $8.98 \pm 0.11$ & $8.44 \pm 0.09$ & $2.53 \pm 0.21$ & $0.13 \pm 0.02$ \\
\hline & 2 & 3 & 12 & $9.43 \pm 0.12$ & $8.49 \pm 0.09$ & $2.97 \pm 0.25$ & $0.19 \pm 0.03$ \\
\hline & 3 & 3 & 8 & $9.08 \pm 0.14$ & $8.57 \pm 0.11$ & $2.68 \pm 0.27$ & $0.17 \pm 0.03$ \\
\hline & 4 & 3 & 6 & $9.03 \pm 0.13$ & $8.74 \pm 0.11$ & $2.58 \pm 0.25$ & $0.15 \pm 0.02$ \\
\hline & 2 & 4 & 12 & $9.26 \pm 0.13$ & $8.87 \pm 0.12$ & $2.98 \pm 0.30$ & $0.16 \pm 0.03$ \\
\hline & 3 & 4 & 8 & $9.01 \pm 0.11$ & $8.83 \pm 0.10$ & $2.58 \pm 0.23$ & $0.13 \pm 0.02$ \\
\hline & 4 & 4 & 6 & $8.97 \pm 0.11$ & $8.83 \pm 0.10$ & $2.59 \pm 0.24$ & $0.13 \pm 0.02$ \\
\hline \multirow{9}{*}{$\begin{array}{l}\text { Classical } \\
\text { Kitting }\end{array}$} & 2 & 2 & 12 & $10.11 \pm 0.14$ & $7.47 \pm 0.06$ & $4.08 \pm 0.29$ & $0.32 \pm 0.04$ \\
\hline & 3 & 2 & 8 & $9.44 \pm 0.14$ & $7.78 \pm 0.08$ & $3.08 \pm 0.29$ & $0.21 \pm 0.04$ \\
\hline & 4 & 2 & 6 & $9.25 \pm 0.13$ & $7.66 \pm 0.07$ & $2.76 \pm 0.25$ & $0.20 \pm 0.03$ \\
\hline & 2 & 3 & 12 & $9.47 \pm 0.14$ & $7.68 \pm 0.07$ & $2.96 \pm 0.27$ & $0.24 \pm 0.04$ \\
\hline & 3 & 3 & 8 & $9.01 \pm 0.11$ & $8.07 \pm 0.07$ & $2.43 \pm 0.22$ & $0.13 \pm 0.02$ \\
\hline & 4 & 3 & 6 & $9.06 \pm 0.15$ & $8.08 \pm 0.09$ & $2.58 \pm 0.29$ & $0.19 \pm 0.05$ \\
\hline & 2 & 4 & 12 & $9.17 \pm 0.13$ & $7.96 \pm 0.08$ & $2.66 \pm 0.27$ & $0.18 \pm 0.03$ \\
\hline & 3 & 4 & 8 & $8.97 \pm 0.12$ & $8.39 \pm 0.09$ & $2.32 \pm 0.23$ & $0.12 \pm 0.02$ \\
\hline & 4 & 4 & 6 & $8.98 \pm 0.14$ & $8.37 \pm 0.09$ & $2.60 \pm 0.28$ & $0.16 \pm 0.04$ \\
\hline \multirow{3}{*}{$\begin{array}{l}\text { Line Feeding } \\
\text { To-Order }\end{array}$} & 2 & \multicolumn{2}{|c|}{ not applicable } & $9.93 \pm 0.12$ & $5.31 \pm 0.06$ & $4.23 \pm 0.24$ & $0.34 \pm 0.03$ \\
\hline & 3 & \multicolumn{2}{|c|}{ not applicable } & $10.13 \pm 0.12$ & $5.38 \pm 0.06$ & $4.23 \pm 0.29$ & $0.27 \pm 0.03$ \\
\hline & 4 & \multicolumn{2}{|c|}{ not applicable } & $10.21 \pm 0.12$ & $5.41 \pm 0.06$ & $4.04 \pm 0.28$ & $0.25 \pm 0.03$ \\
\hline \multirow{3}{*}{$\begin{array}{l}\text { Kitting } \\
\text { To-Order }\end{array}$} & 2 & \multicolumn{2}{|c|}{ not applicable } & $12.29 \pm 016$ & $5.66 \pm 0.07$ & $7.29 \pm 0.39$ & $0.54 \pm 0.05$ \\
\hline & 3 & \multicolumn{2}{|c|}{ not applicable } & $12.31 \pm 0.17$ & $5.69 \pm 0.07$ & $6.88 \pm 0.46$ & $0.47 \pm 0.06$ \\
\hline & 4 & \multicolumn{2}{|c|}{ not applicable } & $12.58 \pm 0.19$ & $5.74 \pm 0.08$ & $7.67 \pm 0.49$ & $0.53 \pm 0.07$ \\
\hline
\end{tabular}


Table 2: Results for different Parts Feeding Policies and Stochastic Processing Times

\begin{tabular}{|c|c|c|c|c|c|c|c|}
\hline & \multirow{2}{*}{$\begin{array}{l}\text { Part } \\
\text { Variants }\end{array}$} & \multirow{2}{*}{$\begin{array}{l}\text { Reorder } \\
\text { Point }\end{array}$} & \multirow{2}{*}{$\begin{array}{l}\text { Reorder } \\
\text { Quantity }\end{array}$} & \multicolumn{4}{|c|}{ Assembly Order } \\
\hline & & & & TTT & TT & \%tardy & Tard. \\
\hline \multirow{9}{*}{$\begin{array}{l}\text { Line } \\
\text { Stocking }\end{array}$} & 2 & 2 & 12 & $18.25 \pm 0.34$ & $15.58 \pm 0.27$ & $24.63 \pm 0.75$ & $2.98 \pm 0.22$ \\
\hline & 3 & 2 & 8 & $16.72 \pm 0.23$ & $14.88 \pm 0.19$ & $20.74 \pm 0.60$ & $2.30 \pm 0.14$ \\
\hline & 4 & 2 & 6 & $15.96 \pm 0.24$ & $14.55 \pm 0.19$ & $18.78 \pm 0.59$ & $1.95 \pm 0.14$ \\
\hline & 2 & 3 & 12 & $17.27 \pm 0.26$ & $15.21 \pm 0.21$ & $22.07 \pm 0.63$ & $2.56 \pm 0.16$ \\
\hline & 3 & 3 & 8 & $16.00 \pm 0.22$ & $14.68 \pm 0.19$ & $19.00 \pm 0.57$ & $1.99 \pm 0.12$ \\
\hline & 4 & 3 & 6 & $15.39 \pm 0.20$ & $14.48 \pm 0.18$ & $17.14 \pm 0.53$ & $1.70 \pm 0.10$ \\
\hline & 2 & 4 & 12 & $16.29 \pm 0.24$ & $14.74 \pm 0.20$ & $19.44 \pm 0.59$ & $2.15 \pm 0.14$ \\
\hline & 3 & 4 & 8 & $15.29 \pm 0.21$ & $14.38 \pm 0.19$ & $17.37 \pm 0.53$ & $1.66 \pm 0.11$ \\
\hline & 4 & 4 & 6 & $14.92 \pm 0.22$ & $14.34 \pm 0.19$ & $16.40 \pm 0.54$ & $1.54 \pm 0.12$ \\
\hline \multirow{9}{*}{$\begin{array}{l}\text { Classical } \\
\text { Kitting }\end{array}$} & 2 & 2 & 12 & $20.24 \pm 0.44$ & $13.16 \pm 0.15$ & $29.11 \pm 0.87$ & $4.12 \pm 0.29$ \\
\hline & 3 & 2 & 8 & $17.34 \pm 0.30$ & $13.20 \pm 0.15$ & $22.23 \pm 0.71$ & $2.54 \pm 0.19$ \\
\hline & 4 & 2 & 6 & $16.46 \pm 0.29$ & $13.50 \pm 0.18$ & $20.18 \pm 0.71$ & $2.21 \pm 0.16$ \\
\hline & 2 & 3 & 12 & $18.69 \pm 0.42$ & $13.40 \pm 0.17$ & $25.34 \pm 0.85$ & $3.42 \pm 0.28$ \\
\hline & 3 & 3 & 8 & $16.13 \pm 0.28$ & $13.38 \pm 0.16$ & $19.13 \pm 0.62$ & $2.05 \pm 0.17$ \\
\hline & 4 & 3 & 6 & $15.70 \pm 0.25$ & $13.74 \pm 0.18$ & $17.99 \pm 0.58$ & $1.88 \pm 0.14$ \\
\hline & 2 & 4 & 12 & $17.19 \pm 0.32$ & $13.58 \pm 0.18$ & $21.67 \pm 0.69$ & $2.63 \pm 0.20$ \\
\hline & 3 & 4 & 8 & $15.64 \pm 0.26$ & $13.72 \pm 0.17$ & $18.04 \pm 0.64$ & $1.83 \pm 0.14$ \\
\hline & 4 & 4 & 6 & $15.05 \pm 0.22$ & $13.91 \pm 0.17$ & $16.62 \pm 0.58$ & $1.55 \pm 0.11$ \\
\hline \multirow{3}{*}{$\begin{array}{l}\text { Line Feeding } \\
\text { To-Order }\end{array}$} & 2 & \multicolumn{2}{|c|}{ not applicable } & $20.24 \pm 0.31$ & $14.15 \pm 0.23$ & $30.00 \pm 0.70$ & $3.49 \pm 0.20$ \\
\hline & 3 & \multicolumn{2}{|c|}{ not applicable } & $20.36 \pm 0.32$ & $14.13 \pm 0.23$ & $30.74 \pm 0.73$ & $3.47 \pm 0.22$ \\
\hline & 4 & \multicolumn{2}{|c|}{ not applicable } & $20.33 \pm 0.26$ & $13.96 \pm 0.19$ & $30.81 \pm 0.67$ & $3.33 \pm 0.17$ \\
\hline \multirow{3}{*}{$\begin{array}{l}\text { Kitting } \\
\text { To-Order }\end{array}$} & 2 & \multicolumn{2}{|c|}{ not applicable } & $23.78 \pm 0.34$ & $13.26 \pm 0.21$ & $40.40 \pm 0.83$ & $5.08 \pm 0.24$ \\
\hline & 3 & \multicolumn{2}{|c|}{ not applicable } & $24.06 \pm 0.36$ & $13.40 \pm 0.21$ & $40.68 \pm 0.83$ & $5.23 \pm 0.26$ \\
\hline & 4 & \multicolumn{2}{|c|}{ not applicable } & $23.76 \pm 0.40$ & $13.24 \pm 0.23$ & $40.00 \pm 0.87$ & $4.99 \pm 0.29$ \\
\hline
\end{tabular}




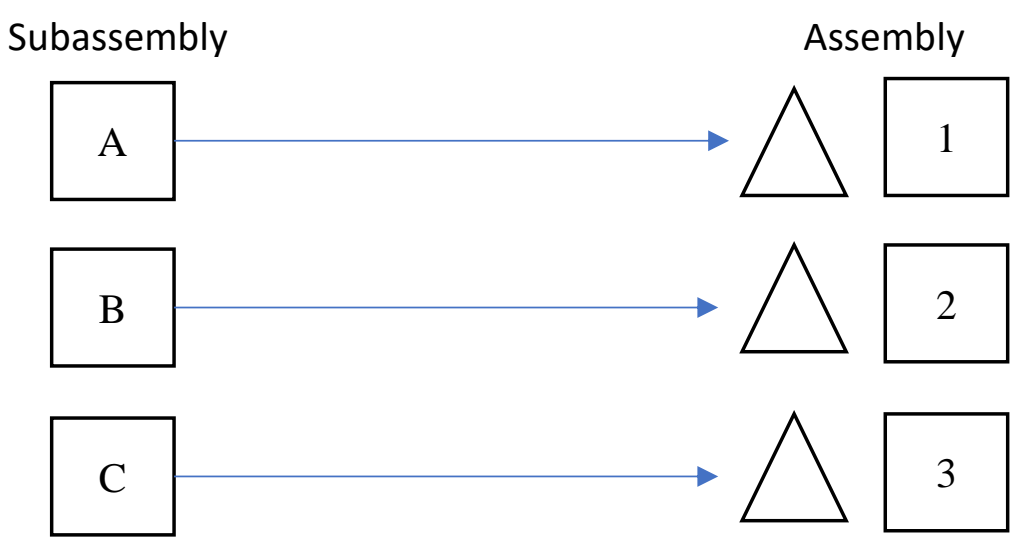

(a) Line stocking and Line Feeding To-Order

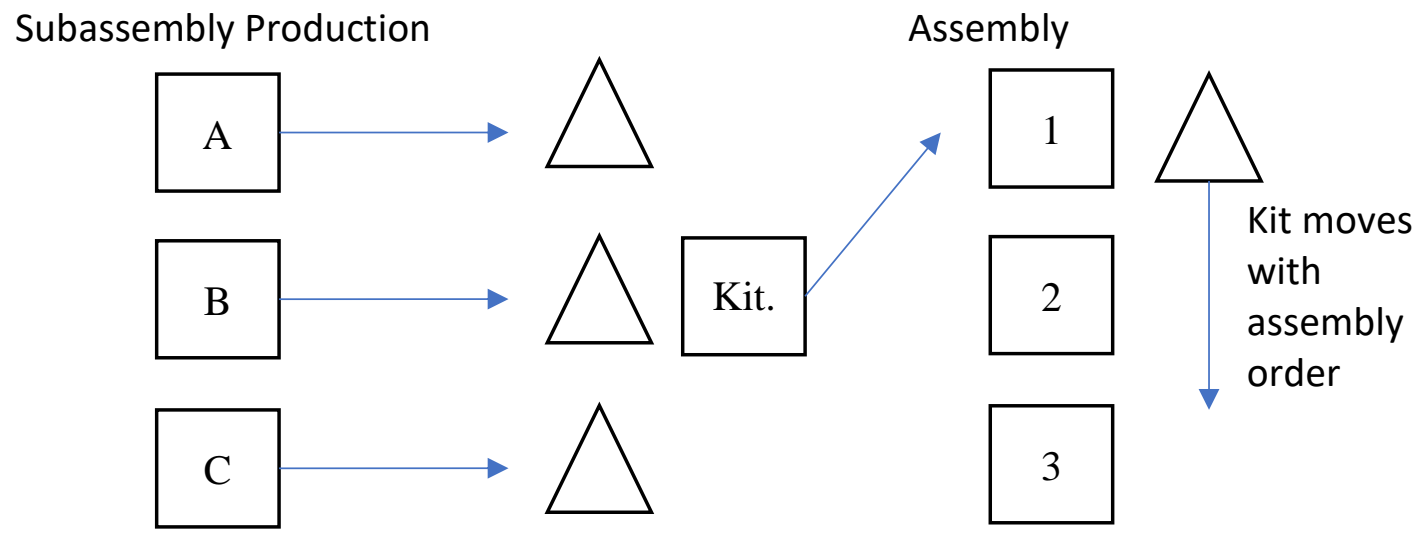

(b) Classical Kitting

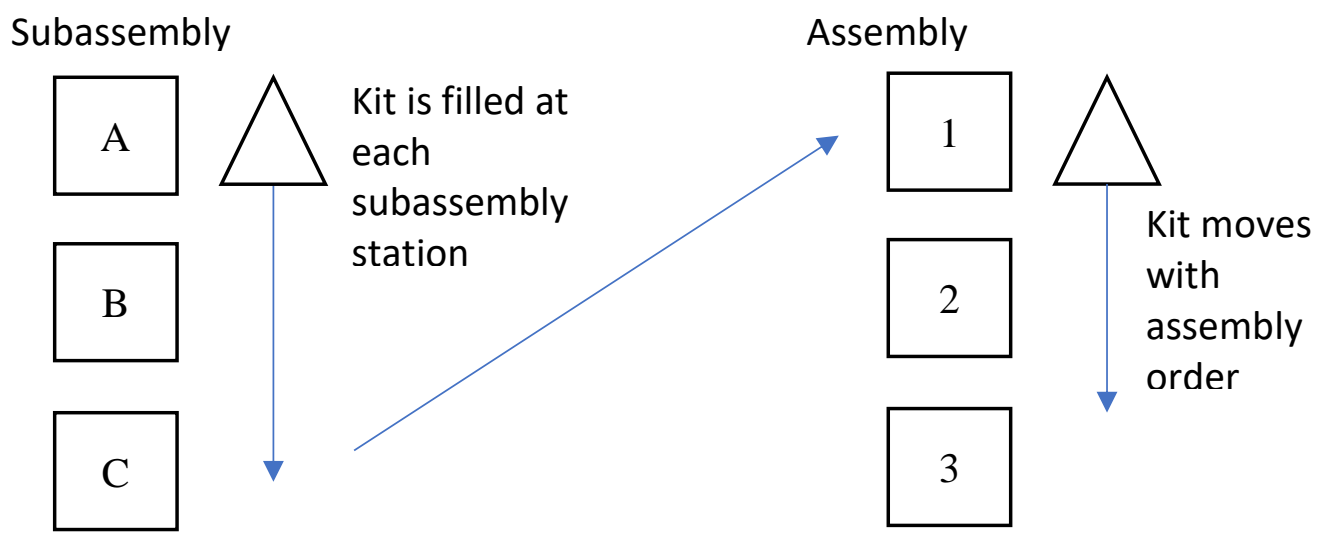

(c) Kitting to Order

Figure 1: Schematization of the Four Different Parts Feeding Policies 